\title{
Desain Sistem Pelayanan Resep Rawat Jalan RSUD Blambangan Melalui Pendekatan User Centered
}

\author{
Outpatients Dispensing System Design at Blambangan Hospital Through User \\ Centered Approach
}

\author{
Hariaty Octavia*, Susi Ari Kristina, Eko Nugroho \\ Program Pascasarjana, Program Studi Ilmu Farmasi, Fakultas Farmasi, Universitas Gadjah Mada \\ Corresponding author: Hariaty Octavia: Email: hariatyoctavia@gmail.com \\ Submitted: 26-04-2019 \\ Revised: 29-04-2019 \\ Accepted: 29-04-2019
}

\begin{abstract}
ABSTRAK
Pelayanan resep rawat jalan meliputi kegiatan administratif dan kegiatan pelayanan farmasi klinik. Kebutuhan pengguna dalam pelayanan resep rawat belum sepenuhnya didukung oleh Hospital Pharmacy Information System (HPIS), sehingga perlu dilakukan desain sistem pelayanan resep rawat jalan di RSUD Blambangan menggunakan pendekatan user centered. Penelitian ini bertujuan membuat desain sistem pelayanan resep rawat jalan di RSUD Blambangan melalui pendekatan user centered yaitu berdasarkan kebutuhan pengguna di instalasi farmasi. Penelitian ini merupakan rancangan deskriptif yaitu analisis kebutuhan pengguna menggunakan metode focus group discussion (FGD) dan telaah dokumen. Subyek penelitian ini berjumlah 24 otang yang terdiri dari 9 orang apoteker, 13 orang tenaga teknis kefarmasian (TTK), dan 2 orang tenaga administrasi. Kebutuhan data dalam pelayanan resep rawat jalan meliputi data pasien, data obat, data admisi, data pemeriksaan fisik, data pemeriksaan klinis, data pemeriksaan laboratorium, dan data pelayanan resep yang selanjutnya dikelompokkan dalam kebutuhan data skrining resep, labeling, dan penyerahan obat. Desain sistem pelayanan resep rawat jalan yang dibuat merupakan desain dalam bentuk data flow diagram (DFD). Kesimpulan penelitian ini adalah perlu dibuat desain model lanjutan pelayanan resep rawat jalan yaitu entity relationship diagram (ERD), data dictionary, dan system flowchart.
\end{abstract}

Kata kunci: Pasien rawat jalan, pelayanan farmasi, kebutuhan data, user-centered

\section{ABSTRACT}

Outpatients dispensing are consisted of administration and clinical pharmacy activities. Userneeds were not have been supported by the Hospital Pharmacy Information System (HPIS), therefore it was necessary to design the outpatients dispensing system at Blambangan Hospital using a usercentered approach. This study aims to design the outpatients dispensing service system at Blambangan Hospital through the user-centered approach in the hospital pharmacy department. This research was a descriptive design, namely the analysis of user needs using the focus group discussion (FGD) method and document review. The subjects of this study amounted to 24 persons consisting of 9 pharmacists, 13 pharmacy technical staffs, and 2 administrative staffs. Data requirements in outpatient dispensing services include patient data, medicines data, admission data, physical examination data, clinical examination data, laboratory examination data, and dispensingprocess data. Furthermore, there were grouped into prescription screening, labeling, and delivery. Outpatients dispensing system design was created in the form of data flow diagram (DFD). The conclusion of this study was necessary to design advanced models for outpatients dispensing services in the form of entity relationship diagram (ERD), data dictionary, and system flowchart. Keywords: outpatients dispensing services, data needs, user-centered

\section{PENDAHULUAN}

Penyediaan informasi yang cepat, tepat dan akurat merupakan salah satu upaya dalam peningkatan pelayanan kesehatan yang berkualitas sebagaimana diatur dalam UndangUndang nomor 44 tahun 2009 tentang Rumah
Sakit khususnya pada pasal 52 (Depkes RI, 2009) dan Permenkes nomor 1171 tahun 2011 tentang Sistem Informasi Rumah Sakit (Kemenkes RI, 2011). Kedua perundangundangan ini mewajibkan rumah sakit untuk melakukan pencatatan dan pelaporan semua 
kegiatan penyelenggaraan rumah sakit dalam bentuk sistem informasi manajemen (SIM).

Pada proses pelayanan resep dapat terjadi medication errors seperti kesalahan dalam membaca resep yang berpotensi menimbulkan adverse drug events (ADEs) (Cohen, 2007). Untuk mencegah terjadinya ADEs apoteker membutuhkan data dan informasi dari sistem informasi manajemen rumah sakit (SIMRS), sehingga diperlukan desain hospital pharmacy information system (HPIS) yang teritegrasi dengan sistem-sistem lain dalam SIMRS. Hal ini dapat digambarkan dalam bentuk arsitektur HPIS seperti pada Gambar 1 (Anderson dkk., 2009).

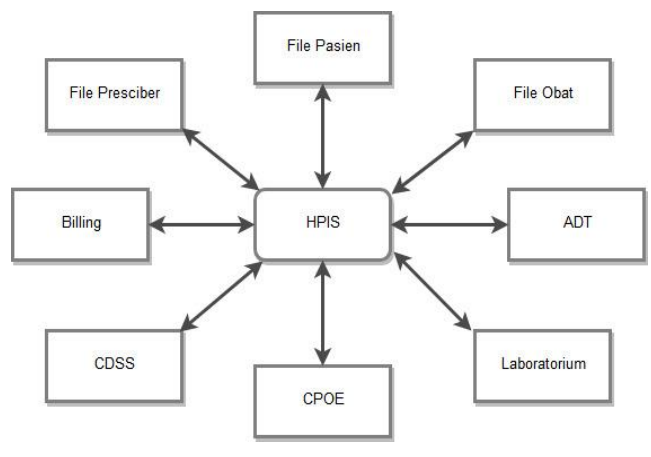

Gambar 1. Arsitektur HPIS

Hasil penelitian Jaelani dkk menyebutkan bahwa skrining klinis pada proses skrining resep merupakan proses yang paling tinggi menimbulkan error, dan hasil evaluasi menggunakan metode performance, information, economic, control, efficiency dan service (PIECES) menunjukkan bahwa desain sistem informasi pada proses skrining resep dapat membantu tenaga farmasi dalam melakukan skrining dan meningkatkan waktu pelayanan resep (Jaelani dkk., 2015). Pelayanan resep pasien rawat jalan di RSUD Blambangan menggunakan SIMRS yang disediakan oleh pihak luar sejak 2012. Pemanfaatan SIMRS dalam pelayanan resep selama ini belum optimal, karena SIMRS belum bisa menyediakan data dan informasi yang dibutuhkan dalam pelayanan resep. Oleh kerena itu perlu dilakukan desain sistem pelayanan resep diantaranya pelayanan resep rawat jalan dengan menggunakan pendekatan user-centered.

Tujuan penelitian ini adalah membuat desain sistem pelayanan resep rawat jalan di
RSUD Blambangan melalui pendekatan kebutuhan pengguna di instalasi farmasi

\section{METODOLOGI}

Penelitian ini merupakan rancangan deskriptif yaitu desain sistem pelayanan resep rawat jalan menggunakan pendekatan user centered. Penelitian dilakukan pada bulan Oktober sampai Nopember 2018 di RSUD Blambangan menggunakan metode focus grup discussion (FGD) dan telaah dokumen. Subyek penelitian ini adalah 9 orang apoteker, 13 orang tenaga teknis kefarmasian (TTK) dan 2 orang tenaga administrasi. Kriteria inklusi pada penelitian ini adalah apoteker aktif, TTK dan tenaga administrasi aktif yang terlibat dalam pelayanan resep rawat jalan, sudah bekerja minimal 2 tahun dan menggunakan SIMRS secara langsung. Desain sistem dilakukan dengan melakukan requirement kebutuhan pengguna yang dilanjutkan dengan analisis kebutuhan data dan mengelompokkannya ke dalam data pasien, data obat, data admisi, data pemeriksaan fisik, pemeriksaan klinis, pemeriksaan laboratorium, dan data pelayanan resep yang dilanjutkan dengan pembuatan desain proses dalam bentuk data flow diagram (DFD).

\section{HASIL DAN PEMBAHASAN}

Penelitian ini diawali dengan melakukan skrining terhadap calon responden FGD dengan menyebarkan form biodata. Terdapat 9 orang apoteker, 21 orang TTK dan tenaga administrasi yang memenuhi kriteria inklusi sebagai subyek penelitian. FGD terbagi dalam 3 kelompok yaitu kelompok apoteker dan 2 kelompok TTK dan tenaga administrasi. Karakteristik responden FGD (Tabel I).

Dalam penyusunan kebutuhan data, peneliti mengacu pada Permenkes nomor 72 tahun 2016 (Kemenkes RI, 2016), Guide to Good Prescribing - a Practical Manual(de Vriez dkk., 1992), guideline labeling oleh Institute for Safe Madication Practices (ISMP)(ISMP, 2010), standar nasional akreditasi rumah sakit (SNARS) edisi 1 (KARS, 2017), dan Keputusan Menteri Kesehatan nomor 129 tahun 2008 (Kemenkes RI, 2008). Kebutuhan data dalam pelayanan resep rawat jalan terbagi dalam kebutuhan pada proses skrining resep, labeling, penyerahan obat, dan sistem pelaporan.

Peneliti menggunakan check list kebutuhan data pada proses pelayanan resep 
Tabel I. Karakteristik Responden FGD

\begin{tabular}{|c|c|c|c|c|}
\hline \multirow{2}{*}{ Karakteristik Responden Penelitian } & \multicolumn{2}{|c|}{ Apoteker } & \multicolumn{2}{|c|}{ TTK $^{1}$ dan Tenaga Administrasi } \\
\hline & $\mathrm{N}=9$ & $\%$ & $n=15$ & $\%$ \\
\hline \multicolumn{5}{|l|}{ Usia } \\
\hline$-\leq 29$ tahun & 7 & 77,8 & 5 & 33,3 \\
\hline$-30-39$ tahun & 2 & 22,2 & 7 & 46,7 \\
\hline - 40-49 tahun & 0 & 0 & 3 & 20,0 \\
\hline$-\geq 50$ tahun & 0 & 0 & 0 & 0 \\
\hline \multicolumn{5}{|l|}{ Jenis Kelamin } \\
\hline - Laki-laki & 3 & 33,3 & 2 & 13,3 \\
\hline - Perempuan & 6 & 66,7 & 13 & 86,7 \\
\hline \multicolumn{5}{|l|}{ Pendidikan Terakhir } \\
\hline - Strata 2 & 2 & 22,2 & 0 & 0 \\
\hline - Strata 1 & 7 & 77,8 & 1 & 6,7 \\
\hline - Diploma 3 & 0 & 0 & 11 & 73,3 \\
\hline - SMA / sederajat & 0 & 0 & 3 & 20 \\
\hline \multicolumn{5}{|l|}{ Masa Kerja di IFRS 2} \\
\hline$-<2$ tahun & 3 & 33,3 & 0 & 0 \\
\hline$-\geq 2$ Tahun & 6 & 66,7 & 15 & 100 \\
\hline \multicolumn{5}{|l|}{ Menggunakan SIMRS 3} \\
\hline$-\mathrm{Ya}$ & 9 & 100 & 15 & 100 \\
\hline - Tidak & 0 & 0 & 0 & 0 \\
\hline \multicolumn{5}{|l|}{ Jenis Tenaga : } \\
\hline - Tenaga Teknis Kefarmasian & & & 13 & 86,7 \\
\hline - Tenaga Administrasi & & & 2 & 13,3 \\
\hline
\end{tabular}

Tabel II. Check List Kebutuhan Data

\begin{tabular}{lcccc}
\hline \multicolumn{1}{c}{ Kategori Data } & $\begin{array}{c}\text { Skrining } \\
\text { Resep }\end{array}$ & Labeling & $\begin{array}{c}\text { Penyerahan } \\
\text { Obat }\end{array}$ & $\begin{array}{c}\text { Sistem } \\
\text { Pelaporan }\end{array}$ \\
\hline Data pasien & $\sqrt{ }$ & $\sqrt{ }$ & $\sqrt{ }$ & $\sqrt{ }$ \\
Data Obat & $\sqrt{ }$ & $\sqrt{ }$ & & \\
Data Pemeriksaan Fisik & $\sqrt{ }$ & & & \\
Data Pemeriksaan Klinis & $\sqrt{ }$ & & & $\sqrt{ }$ \\
Data Pemeriksaan & $\sqrt{ }$ & & $\sqrt{ }$ & \\
Laboratorium & $\sqrt{ }$ & $\sqrt{ }$ & & \\
Data pelayanan resep & $\sqrt{ }$ & & & \\
\hline
\end{tabular}

rawat jalan (Tabel II) untuk membantu dalam melakukan analisis kebutuhan data.

\section{Kebutuhan Data Skrining Resesp}

Handwriting prescription serta kurang lengkapnya data dan informasi yang dibutuhkan dalam pelayanan resep rawat jalan di RSUD Blambangan merupakan permasalahan yang berpotensi menyebabkan medication errors. Resep dan instruksi penggunaan obat yang diinput oleh petugas instalasi farmasi berpotensi menyebabkan kesalahan dalam memilih obat dan kesalahan dalam memilih instruksi penggunaan. Hasil wawancara dengan apoteker penanggung jawab depo farmasi rawat jalan, kadang masih ditemukan resep tulisan tangan perawat, sehingga apoteker membutuhkan waktu untuk melakukan penelusuran riwayat pengobatan pasien sebelumnya. Adanya duplikasi pengobatan juga ditemukan pada pasien yang mendapatkan resep dari poliklinik yang berbeda. Perubahan dosis dan waktu penggunaan obat menjadi salah satu perhatian saat dilakukan proses skrining resep, terlebih resep masih di-input oleh petugas instalasi farmasi.

Hasil penelitian Hertati dkk menyimpulkan bahwa administration error dan 
Tabel III. Kebutuhan Data Skrining Administratif

\begin{tabular}{lcc}
\hline \multirow{2}{*}{ Kebutuhan Data Skrining Administratif } & \multicolumn{3}{c}{ Jenis data } & Admisi \\
\cline { 2 - 3 } Nama pasien* & Pasien & \\
Umur pasien* & $\sqrt{ }$ & \\
Alamat tinggal saat ini* & $\sqrt{ }$ & \\
Jenis kelamin & $\sqrt{ }$ & \\
Nomor medical record & $\sqrt{ }$ & \\
Bar-code pasien & $\sqrt{ }$ & $\sqrt{ }$ \\
Tanggal pendaftaran & & $\sqrt{ }$ \\
Nomor SEP1 & & $\sqrt{ }$ \\
Tanggal SEP1 & & $\sqrt{ }$ \\
Nomor SJP2 & & $\sqrt{ }$ \\
Tanggal SJP2 & & \\
\hline
\end{tabular}

Keterangan : *Berdasarkan Permenkes No. 72 tahun 2016, ${ }^{1}$ Surat Eligibilitas Pasien, ${ }^{2}$ Surat Jaminan Pelayanan.

dispensing error merupakan penyebab medication errors terbesar pada pasien intensive care unit (ICU) RSUD Kota Baubau dan RS Santa Ana Kendari, sedangkan prescribing error merupakan yang terkecil menyebabkan medication erros (Hertati dkk., 2014). Dispensing error dan prescribing error dapat dicegah dengan penerapan e-prescription. Penelitian Oktaviani dkk menyebutkan $e$-prescription dapat menunjukkan adanya duplikasi terapi dan obatobat yang berpotensi saling berinteraksi (Oktafiani dkk., 2012). Duplikasi terapi dan interaksi obat dapat dicegah dengan melakukan skrining terhadap resep.

Permasalahan yang sering ditemukan saat skrining resep pasien rawat jalan di RSUD Blambangan seperti tidak lengkapnya data pasien yang ditulis dalam resep, adanya duplikasi pengobatan, adanya perubahan waktu penggunaan obat, perubahan dosis individual, dan tulisan dalam resep yang tidak terbaca. Kebutuhan data skrining resep pada penelitian ini menggunakan acuan Permenkes nomor 72 tahun 2016 dan kebutuhan pengguna (Tabel III dan Tabel IV).

\section{Kebutuhan Data Labeling}

Kekeliruan penulisan dalam label obat menyebabkan medication errors, sehingga perlu keseragaman dalam penulisan pada label, terutama pada penulisan konsentrasi obat dan obat dalam kategori look alike sound alike (LASA) (Hohenstein dkk., 2016).

Instalasi farmasi RSUD Blambangan sudah menggunakan e-label dalam pelayanan resep, namun informasi penggunaan obat yang tertulis dalam label sangat minim, sehingga masih berpotensi menimbulkan medication errors. Kebutuhan data pada proses labeling menggunakan guideline ISMP dan kebutuhan pengguna pada proses skrining resep (Tabel V).

\section{Kebutuhan Data Penyerahan Obat}

Pada proses penyerahan obat, dilakukan pemeriksaan kesesuaian obat dengan resep meliputi nama obat, kekuatan, jumlah, rute penggunaan, waktu penggunaan dan dosis individual juga dilakukan pemeriksaan kesesuaian data pasien dalam resep, label dan penerima obat. Pemeriksaan kesesuaian obat dan data pasien untuk memastikan kembali bahwa pasien sudah menerima obat yang benar. Penggunaan teknologi bar-code yaitu electronic medication-administra-tion system (eMAR) dalam penelitian Poon dkk dapat menurunkan kejadian medication errors di farmasi sebesar 67\% (Poon dkk., 2010). (Proses 1.0), Nursing Information System (Proses 2.0) Analisis kebutuhan data pada proses penyerahan obat menggunakan acuan SNARS edisi 1 dan kebutuhan pengguna (Tabel VI).

\section{Desain Model Data Flow Diagram (DFD)}

Desain model dalam bentuk DFD (Gambar 2) proses pelayanan resep rawat jalan (Proses 5.0) di RSUD Blambangan, HPIS dipengaruhi oleh 9 elemen lingkungan eksternal, dan berbagi data dengan sistem informasi lain dalam SIMRS. Menurut Anderson dkk. HPIS dipengaruhi sistem informasi lain 
Tabel IV. Kebutuhan Data Skrining Farmasetis dan Klinis

\begin{tabular}{|c|c|c|c|c|c|}
\hline \multirow[b]{2}{*}{$\begin{array}{l}\text { Kebutuhan Skrining } \\
\text { Farmasetis dan Klinis }\end{array}$} & \multicolumn{5}{|c|}{ Jenis data } \\
\hline & $\begin{array}{c}\text { Pemeriksaan } \\
\text { Fisik }\end{array}$ & $\begin{array}{l}\text { Pemeriksaan } \\
\text { Klinik }\end{array}$ & $\begin{array}{c}\text { Pemeriksaan } \\
\text { Lab }\end{array}$ & Obat & $\begin{array}{l}\text { Pelay. } \\
\text { Resep }\end{array}$ \\
\hline Hasil pemeriksaan fisik & $\sqrt{ }$ & & & & \\
\hline $\begin{array}{l}\text { Hasil pemeriksaan } \\
\text { laboratorium }\end{array}$ & & & $\sqrt{ }$ & & \\
\hline Nama dokter* & & $\sqrt{ }$ & & & \\
\hline Tanggal penulisan resep* & & $\sqrt{ }$ & & & \\
\hline Nama poliklinik, instalasi / rua & gan* & $\sqrt{ }$ & & & \\
\hline Nama generik* & & & & $\sqrt{ }$ & \\
\hline Nama brand* & & & & $\sqrt{ }$ & \\
\hline Satuan dosis & & & & $\sqrt{ }$ & \\
\hline Kekuatan obat* & & & & $\sqrt{ }$ & \\
\hline Dosis individual & & $\sqrt{ }$ & & & \\
\hline Kegunaan obat* & & $\sqrt{ }$ & & & \\
\hline Jumlah obat yang diresepkan & & $\sqrt{ }$ & & & \\
\hline Frekuensi penggunaan & & $\sqrt{ }$ & & & \\
\hline Instruksi penggunaan* & & $\sqrt{ }$ & & & \\
\hline Rute penggunaan* & & $\sqrt{ }$ & & & \\
\hline Tanggal obat habis & & $\sqrt{ }$ & & & \\
\hline Waktu penggunaan & & $\sqrt{ }$ & & & \\
\hline Kelas terapi Fornas & & & & $\sqrt{ }$ & \\
\hline Kategori formularium obat & & & & $\sqrt{ }$ & \\
\hline Peresepan maksimal & & & & $\sqrt{ }$ & \\
\hline Polifarmasi & & $\sqrt{ }$ & & & \\
\hline ICD $10 * 1$ & & $\sqrt{ }$ & & & \\
\hline Penyakit komorbid* & & $\sqrt{ }$ & & & \\
\hline Kategori obat penyakit kronis & & & & $\sqrt{ }$ & \\
\hline Kategori crushed tablet & & & & $\sqrt{ }$ & \\
\hline Nomor resep & & & & & $\sqrt{ }$ \\
\hline Kode obat dan BMHP2 & & & & $\sqrt{ }$ & \\
\hline Bar-code obat* & & & & $\sqrt{ }$ & $\sqrt{ }$ \\
\hline Jumlah obat yang dilayani & & & & & $\sqrt{ }$ \\
\hline $\mathrm{HNA}^{3}$ & & & & $\sqrt{ }$ & \\
\hline $\mathrm{HJA}^{4}$ & & & & $\sqrt{ }$ & \\
\hline Interaksi Obat & & & & & $\sqrt{ }$ \\
\hline $\begin{array}{l}\text { Reaksi obat yang tidak } \\
\text { dikehendaki }\end{array}$ & & & & $\sqrt{ }$ & \\
\hline Riwayat pengobatan pasien & & & & & $\sqrt{ }$ \\
\hline Nomor copy resep & & & & & $\sqrt{ }$ \\
\hline Nama apoteker & & & & & $\sqrt{ }$ \\
\hline Nomor SIPA $^{5}$ & & & & & $\sqrt{ }$ \\
\hline SOAP ${ }^{6}$ Apoteker & & & & & $\sqrt{ }$ \\
\hline Nama TTK ${ }^{7}$ & & & & & $\sqrt{ }$ \\
\hline
\end{tabular}

Keterangan: *Berdasarkan Permenkes nomor 72 tahun 2016 dan buku Guide to Good Prescribing a Practical Manual, ${ }^{1}$ international classification of diseases $10^{\text {th }},{ }^{2}$ bahan medis habis pakai, ${ }^{3}$ harga netto apotik, ${ }^{4}$ harga jual apotik, ${ }^{5}$ surat ijin praktek apoteker, ${ }^{6}$ subjective, objective, assesment, and plan, 7 tenaga teknis kefarmasian 
Tabel V. Kebutuhan Data Labeling

\begin{tabular}{|c|c|c|c|c|c|}
\hline \multirow[b]{2}{*}{ Kebutuhan Data Labeling } & \multicolumn{5}{|c|}{ Jenis data } \\
\hline & Pasien & $\begin{array}{c}\text { Pemeriksaan } \\
\text { Fisik }\end{array}$ & $\begin{array}{c}\text { Pemeriksaan } \\
\text { Klinik }\end{array}$ & Obat & $\begin{array}{c}\text { Pelayanan } \\
\text { Resep }\end{array}$ \\
\hline Nomor medical record & $\sqrt{ }$ & & & & \\
\hline Nama pasien* & $\sqrt{ }$ & & & & \\
\hline Tanggal penulisan resep* & & & $\sqrt{ }$ & & \\
\hline Nama brand* & & & & $\sqrt{ }$ & \\
\hline Nama generik * & & & & $\sqrt{ }$ & \\
\hline Kekuatan obat* & & & & $\sqrt{ }$ & \\
\hline Satuan dosis* & & & & $\sqrt{ }$ & \\
\hline Bentuk obat* & & & & $\sqrt{ }$ & \\
\hline Instruksi penggunaan* & & & $\sqrt{ }$ & & \\
\hline Frekuensi penggunaan & & & $\sqrt{ }$ & & \\
\hline Rute penggunaan* & & & $\sqrt{ }$ & & \\
\hline Kegunaan obat* & & & $\sqrt{ }$ & & \\
\hline Nama dokter* & & & $\sqrt{ }$ & & \\
\hline Nama poliklinik, & & & & & \\
\hline instalasi/ruangan* & & $\sqrt{ }$ & & & \\
\hline Jumlah obat yang dilayani* & & & & $\sqrt{ }$ & \\
\hline Dosis individual* & & & $\sqrt{ }$ & & \\
\hline Waktu penggunaan* & & & $\sqrt{ }$ & & \\
\hline Cara menyiapkan obat & & & & & $\sqrt{ }$ \\
\hline Suhu penyimpanan* & & & & $\sqrt{ }$ & \\
\hline Expired Date* & & & & $\sqrt{ }$ & \\
\hline Beyond Use Date* & & & & & $\sqrt{ }$ \\
\hline Tanggal pelayanan resep* & & & & & $\sqrt{ }$ \\
\hline Depo Farmasi & & & & & $\sqrt{ }$ \\
\hline Alamat $\mathrm{RS}^{* 1}$ & & & & & $\sqrt{ }$ \\
\hline Nomor telepon depo farmasi* & & & & & $\sqrt{ }$ \\
\hline Nomor resep* & & & & & $\sqrt{ }$ \\
\hline Tanggal obat habis & & & & & $\sqrt{ }$ \\
\hline
\end{tabular}

Keterangan : *Berdasarkan guideline ISMP, ${ }^{1}$ Rumah Sakit

di SIMRS seperti ADT Information System Laboratorium Information System (Proses 4.0), Clinical Information System (Proses 3.0), EMR Information System (Proses 6.0) dan Billing Information System (Proses 7.0) (Anderson dkk., 2009). Pasien yang telah mendaftar pada bagian admisi, operator meng-input data pasien dan memilih poliklinik yang dituju. Setelah pasien berada di poliklinik, perawat meng-input data pemeriksaan fisik, dilanjutkan dengan input data pemeriksaan klinis oleh dokter. Setelah dokter menulis resep dalam bentuk $e$ prescribing, pasien menuju depo farmasi dengan menyerahkan kartu pasien yang memuat bar-code pasien untuk mendapatkan pelayanan resep. Data dan informasi pada proses pelayanan resep ini selanjutnya digunakan dalam sistem pelaporan.

\section{KESIMPULAN}

Berdasarkan hasil desain sistem pelayanan resep rawat jalan dalam bentuk DFD, perlu dilakukan desain lanjutan dalam bentuk entity relationship diagram (ERD), data dictionary, dan system flowchart sehingga akan menghasilkan sistem pelayanan resep rawat jalan yang cepat, efektif dan efisien yang dapat mencegah terjadinya medication errors.

\section{UCAPAN TERIMA KASIH}

Ucapan terima kasih kami sampaikan kepada PPSDMK atas bantuan biaya penelitian dan pihak-pihak yang telah membantu saat pengambilan data sampai penyusunan naskah tesis dan naskah publikasi, manajemen RSUD Blambangan, responden di instalasi farmasi RSUD Blambangan, rekan-rekan apoteker 


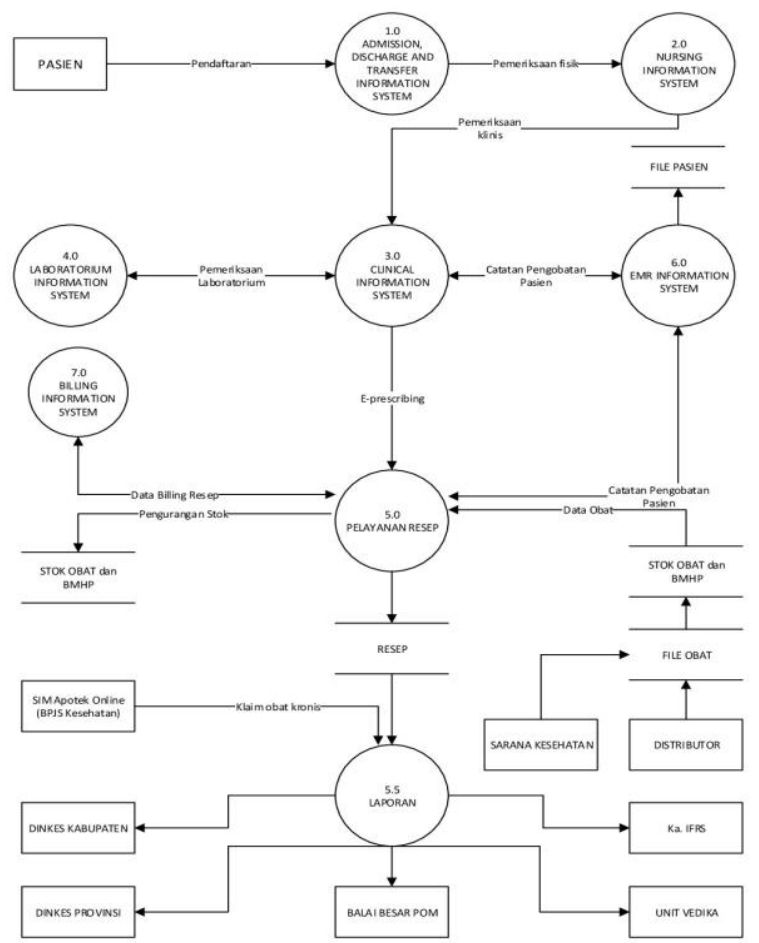

Gambar 2. Desain Model DFD Pelayanan Resep Rawat Jalan RSUD Blambangan

Tabel VI. Kebutuhan Data Penyerahan Obat

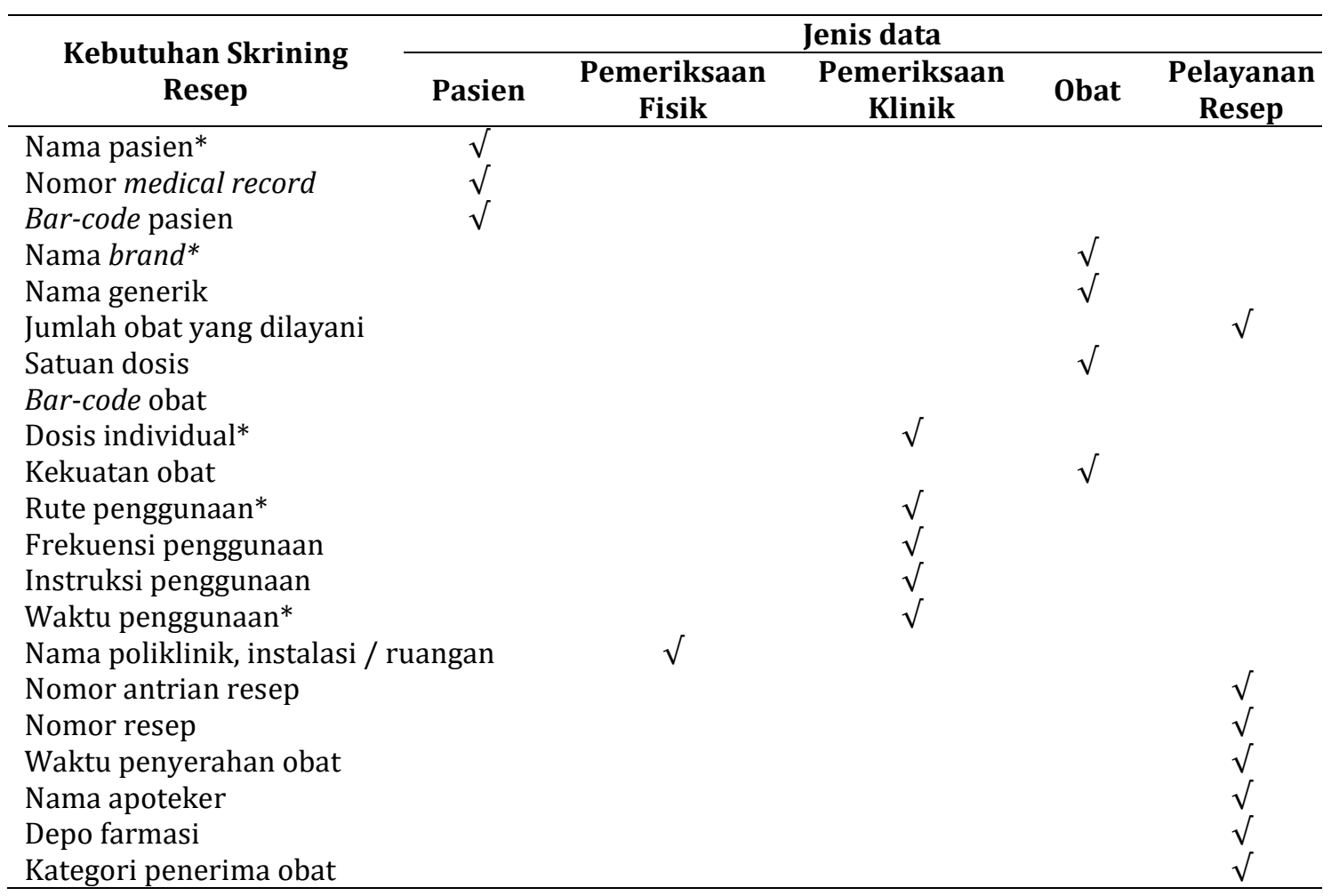

Keterangan: *Berdasarkan standar nasional akreditasi nasional edisi $1,{ }^{1}$ subjective, objective, assesment and plan 
Lia Puspita Sari, Sri Muanisah dan Zulfa Mazidah dari PC IAI Kabupaten Banyuwangi yang telah meluangkan waktu untuk membantu pengambilan data. Tidak lupa ucapan terima kasih kepada Ibu DR. Susi Ari Kristina, M.Kes. Apt. dan bapak DR. Ir. Eko Nugroho, M.Si. atas saran dan masukannya.

\section{DAFTAR PUSTAKA}

Anderson, P.O., McGuinness, S.M., dan Bourne, P.E., 2009. Pharmacy Informatics. CRC Press.

Cohen, M.R., 2007. Medication Errors, 2nd ed. American Pharmacist Association, Washington D.C.

de Vriez, T., Henning, R., Hogerzeil, H., dan Fresle, D., 1992. Guide to Good Prescribing - A Practical Manual.

Depkes RI, 2009. Undang-Undang Nomor 44 Tahun 2009 tentang Rumah Sakit. Departemen Kesehatan RI, Jakarta.

Hertati, Lolok, N.H., Fudholi, A., dan Satibi, 2014. Analisis Kejadian Medication Error pada Pasien ICU. Jurnal Manajemen Dan Pelayanan Farmasi, 4: 8.

Hohenstein, C., Fleischmann, T., Rupp, P., Hempel, D., Wilk, S., dan Winning, J., 2016. German critical incident reporting system database of prehospital emergency medicine: Analysis of reported communication and medication errors between 2005-2015. World Journal of Emergency Medicine, 7: 90-96.
ISMP, 2010. Principles of Designing A Medication Label for Community and Mail Order Pharmacy Prescription Packages.

Jaelani, A.K., Andayani, T.M., dan Sampurno, 2015. Pengembangan Model Sistem Informasi Manajemen Skrining Resep Pasien Rawat Jalan di Puskesmas Wilayah Kota Yogyakarta. Jurnal Manajemen Dan Pelayanan Farmasi, 5: 292-302.

KARS, 2017. Standar Nasional Akreditasi Rumah Sakit Edisi 1.

Kemenkes RI, 2008. Kepmenkes Nomor 129 Tahun 2008 Tentang Standar Pelayanan Minimal Rumah Sakit. Kementerian Kesehatan RI, Jakarta.

Kemenkes RI, 2011. Permenkes Nomor 1171 Tahun 2011 tentang Sistem Informasi Rumah Sakit.

Kemenkes RI, 2016. Permenkes Nomor 72 tahun 2016 Tentang Standar Pelayanan Kefarmasian di Rumah Sakit. Kementerian Kesehatan RI, Jakarta.

Oktafiani, Z., Lazuardi, L., dan Kusnanto, H., 2012. Analisa Pola Peresepan Berdasarkan Peresepan Elektronik di Puskesmas Gunung Kidul. Jurnal Manajemen Pelayanan Farmasi, 2: 220-224.

Poon, E.G., Keohane, C.A., Yoon, C.S., Ditmore, M., Bane, A., Levtzion-Korach, O., dkk., 2010. Effect of Bar-Code Technology on the Safety of Medication Administration. New England Journal of Medicine, 362: 16981707. 